\title{
Associations between body dissatisfaction, importance of appearance, and aging anxiety with depression, and appearance-related behaviors in women in mid-life
}

Isabelle Carrard ${ }^{1}$, Marios Argyrides ${ }^{2}$, Xaris Ioannou ${ }^{2}$, Ingela Lundin Kvalem³ ${ }^{3}$ Karin Waldherr ${ }^{4}$, Diana Harcourt ${ }^{5}$, Siobhan McArdle ${ }^{6}$.

${ }^{1}$ University of Applied Sciences and Arts Western Switzerland (HES-SO), Geneva, Switzerland

${ }^{2}$ Neapolis University Pafos, Cyprus

${ }^{3}$ University of Oslo, Norway

${ }^{4}$ FernFH Distance-Learning University of Applied Sciences, Wiener Neustadt, Austria ${ }^{5}$ Centre for Appearance Research, University of the West of England, Bristol, England ${ }^{6}$ School of Health and Human Performance, Dublin City University, Ireland

Corresponding author:

Isabelle Carrard - isabelle.carrard@ hesge.ch

ORCID-profiles

Isabelle Carrard 0000-0002-2384-6696

Ingela Lundin Kvalem 0000-0003-2406-2102

Karin Waldherr 0000-0002-5852-2237

Diana Harcourt 0000-0002-4285-5678

Siobhain McArdle 0000-0002-8534-4085

Wordcount: 5,608 (incl references, excl. tables) 


\begin{abstract}
The impacts of body dissatisfaction have been widely studied among adolescent girls, but much less in women in mid-life. In this study, we evaluated the associations between body dissatisfaction, psychological health and behaviors used to manage age-related changes, in an online survey of 331 women aged 4565. Body dissatisfaction, importance of appearance and aging anxiety were associated with higher depression scores. Moreover, importance of appearance and aging anxiety were associated with the probability of using "anti-aging" behaviors. It seems that with age, for a subgroup of women, the pressure to stay young may be added to that of staying thin.
\end{abstract}

\title{
Keywords
}

body dissatisfaction, aging anxiety, appearance, women, middle-age 


\section{Introduction}

Body dissatisfaction is a strong risk factor for eating disorders in young female adolescents (Stice, 2002; Stice, Gau, Rohde, \& Shaw, 2017), and is associated prospectively with unhealthy weight control behaviors (Neumark-Sztainer, Paxton, Hannan, Haines, \& Story, 2006). Moreover, body dissatisfaction has been related to other aspects of mental health, being predictive of low self-esteem and depressed mood (Paxton, Neumark-Sztainer, Hannan, \& Eisenberg, 2006; Sharpe et al., 2018). A prospective study conducted on 1,177 adolescent girls also showed that body dissatisfaction was even a stronger predictor of eating symptoms and psychological distress than dietary restraint (Johnson \& Wardle, 2005). Whereas body dissatisfaction and its correlates have been extensively studied in young girls and college-aged populations, much less research has focused on women in mid-life.

\section{Prevalence and age-related changes in body satisfaction}

In spite of the focus of a large proportion of research in this field on young adult populations, Kilpela, Becker, Wesley, and Stewart (2015) note that there is no valid reason to believe that the high prevalence of body image concerns observed among young women would suddenly disappear after graduation from university. On the contrary, the authors observe that, whereas body dissatisfaction in adolescent girls is generally associated with the sociocultural pressure on thinness, it might become more complex with age because of the additional pressure that the Western society exerts on youth. In our Western culture, which admires both thinness and youth, middle-aged and older women have to deal with appearance changes that cosmetics cannot hide entirely (Saucier, 2004) and that can be distressing. Hormonal fluctuations, child birth, and menopause are associated with weight gain and changes in body distribution, hair becomes grey, and the skin displays signs of aging, such as wrinkles or dark spots 
(McLaren \& Kuh, 2004; Peat, Peyerl, \& Muehlenkamp, 2008; Slevec \& Tiggemann, 2011; Takahashi, Fukushima, Kondo, \& Ichihashi, 2017). With age, these changes move the women's body away from the Western beauty standards of thinness and youth.

In fact, several studies have found that body dissatisfaction is relatively stable across the life span. Percentages of body dissatisfaction as high as nearly $80 \%$ were reported in a sample of 1,026 middle-aged (54 year old) women, regardless of body size (McLaren \& Kuh, 2004). In a nonclinical sample of 1,000 women aged 60-70 years, $60.6 \%$ of overweight women (body mass index $(\mathrm{BMI})>25)$ and $50.6 \%$ of normal weight women stated that they did not like their body (Mangweth-Matzek et al., 2006). Another large-scale study $(N=5,868)$ examined age differences in body dissatisfaction in the United States by calculating discrepancies between preferred and current silhouette on figure rating scales (Runfola et al., 2013). Prevalence of body dissatisfaction reached $90.0 \%$ in the $25-34$ group, $93.2 \%$ in the $35-44$ group, $88.9 \%$ in the $45-54$ group, $89.0 \%$ in the $55-54$ group, $88.2 \%$ in the $65-74$ group and $71.9 \%$ in the $75+$ group. Even if body dissatisfaction seemed to decrease with age, this was no longer the case after controlling for BMI. The slight improvement in body evaluation often observed in older age has been suggested to be the result of decreasing BMI after the age of 60 , and of a changed focus from appearance to body function (Gagne et al., 2012).

\section{The importance of appearance might become less prevalent with age}

The presence of body dissatisfaction across the lifespan suggests an ongoing internalization of Western society beauty standards. This was also revealed in findings from unstructured interviews of women aged 61 to 92, who described their aging body in negative terms, denying that they might be judged as desirable, whilst underlining 
how good health and independence were more important than attractiveness (Hurd, 2000). This illustrates a possible reduction in the importance of appearance in the perception of the self with age, which may explain how women cope with body changes, helping them to put things into perspective (Tiggemann \& Lynch, 2001). Importance of appearance might evolve differently than body satisfaction and decrease, although body dissatisfaction stays relatively present. However, this decrease has not regularly been observed in studies in older women. For example, Webster and Tiggemann (2003) found in a sample of 106 women aged between 20 and 65 that body dissatisfaction and importance of appearance did not decrease with age. Further evidence suggests that importance of appearance is consistently present across this age range: In women aged 35-65, importance of appearance has been shown to be significantly associated with weight and shape concerns, BMI and self-care, without any correlation emerging between the importance of appearance and age, supporting a stability of the construct (McLean, Paxton, \& Wertheim, 2010). These results should probably not be seen as that contradictory. They are rather due to a variation of the age range considered in the studies that examined "middle-aged" or "older" women. From these studies, a continuity in the prevalence of body dissatisfaction and importance of appearance seems to be found in samples aged up to 65 years at least.

\section{Behavioral consequences of body dissatisfaction with age}

With body dissatisfaction being still present with age, the unhealthy weight control behaviors associated do not decrease either. This stability of concerns and unhealthy behaviors was illustrated in a survey of 1,849 women aged 50 and older (Gagne, et al., 2012). In this study, $79.1 \%$ said that shape and weight were moderately to mostly important to their self-perception, $71.2 \%$ were currently trying to lose weight, $41.2 \%$ reported checking their body size or shape daily or more, and $40 \%$ said that they 
weighed themselves twice a week or more. These findings illustrate how women are concerned with these issues beyond the age of 50. Moreover, women often gain weight with menopause, and higher BMI, an ideal weight lower than the current one, and lower body satisfaction have been correlated with more disordered eating in post-menopausal women (Goncalves, Silva, \& Gomes, 2015; Slevec \& Tiggemann, 2011). This highlights the role of BMI in problematic eating behaviors in the postmenopausal period, similarly as in younger samples. As summarized in a recent review, eating disorders and disordered eating occur in women at all ages, and menopause might be a critical period, similar to puberty, causing appearance changes requiring a self-concept adaptation (Mangweth-Matzek \& Hoek, 2017).

But thinness is not the only concern that can have consequences in aging women. A youthful appearance is also important for their self-construct, as shown in a qualitative study which highlighted that greying hair was a major concern, with weight gain, of white heterosexual women aged 46-71 years (Winterich, 2007). This led women to diet or dye their hair, instead of challenging Western beauty standards. Similarly, in the study by Gagne et al. (2012), women with higher BMI reported greater shape and weight concerns, whilst those with lower BMI were more concerned with their skin, highlighting the various negative impacts that aging can have on the selfimage.

Some women find it difficult to manage the changes to appearance that occur with age, with the adoption of "anti-aging" behaviors as a potential consequence. In order to assess this, Slevec and Tiggeman (2010) examined the correlates of cosmetic surgery in a survey of 108 women aged 35-55 years. They observed that body dissatisfaction, appearance investment, aging anxiety (the anxiety of appearance changes that come with age), and media exposure predicted the women's attitude 
toward cosmetic surgery. These findings emphasized that body dissatisfaction, importance of appearance, and aging anxiety not only had an impact on weight control behaviors but also on anti-aging behaviors such as cosmetic surgery. An association between aging anxiety and body dissatisfaction was also supported in an Internet survey of 290 women aged 45-60 years (Midlarsky \& Nitzburg, 2008). These results underline that aging anxiety has to be taken into account in research with older women. In a qualitative study of women's perception of natural versus unnatural aging (aged 50-70 years), the majority adhered to cultural norms that associate beauty with youth, and used some form of beauty modification such as cosmetics, anti-wrinkle creams and hair dying (Clarke \& Griffin, 2007). The distinction between natural and unnatural aging was the use of surgical and non-surgical cosmetic procedures. Clarke and Griffin (2007, p. 198) noticed that some women totally subscribed to the sociocultural youth ideals of beauty and associated natural aging with a "moral and physical capitulation to the ravages of time".

\section{Body dissatisfaction and psychological health}

The few studies on body dissatisfaction and its correlates which have been conducted with women in mid-life have mainly focused on the relationships between body dissatisfaction and disordered eating behaviors (Mangweth-Matzek, Hoek, \& Pope, 2014; Slevec \& Tiggemann, 2011). Because a thin and young body is associated with success and social acceptance particularly for women, difficulties in dealing with distancing oneself from beauty standards could also lead women to depression, loss of self-esteem and anxiety (Saucier, 2004). In their review on body image in adult women, Kilpela, et al. (2015) could only retrieve one study that examined the relationship between body dissatisfaction and depressed mood in adult women, without considering it as a comorbidity of eating disorders (Jackson et al., 2014). This study showed that 
women aged between 42-52 years who felt "unattractive" had higher odds of obtaining scores revealing levels of clinically significant depressive symptoms, controlling for BMI.

Given the continuity of the prevalence of body dissatisfaction and of the importance of appearance in women in mid-life, and the relevance of aging anxiety to explain the adoption of anti-aging behaviors, we were interested in the present study in examining the association between body dissatisfaction, importance of appearance, aging anxiety, and depression, as well as with behaviors used to manage age-related physical changes in women in mid-life, defined as being aged between 45 and 65 years. We hypothesized that body dissatisfaction, importance of appearance, and aging anxiety would be positively correlated with depression, and with the use of anti-aging behaviors. BMI and age were included as independent variables in the analyses, because of their potential influences on body dissatisfaction and on importance of appearance (Gagne, et al., 2012; Webster \& Tiggemann, 2003).

\section{Material and methods}

The data analyzed in the present study were collected during a cross-cultural project conducted by a working group of the European COST Action "Appearance Matters: Tackling the Physical and Psychosocial Consequences of Dissatisfaction with Appearance" (COST IS1210, 2013-2017). Partners from seven countries - Austria, Belgium, Cyprus, Ireland, Norway, UK, and Switzerland - took part in the conception of the project. We all agreed on a common questionnaire that included subscales from questionnaires validated in most of the languages represented in the work group. Each country administered an electronic questionnaire in its own language and disseminated the link to a convenience sample in order to collect data from the general community. Only the data collected by the Swiss partner are reported in this paper. 


\section{Participants}

Eligible women were French-speaking and aged between 45 and 65 years. Data were collected online, anonymously, and could not be traced back to the participant. For this reason, the ethical committee of the canton of Geneva confirmed that the study was exempted of ethical approval, because it was beyond the scope of the Swiss law on research on human being (LRH).

Out of 341 women who answered the questionnaire, 9 did not match the age range and one had an impossible value for height. Therefore, 331 participants were included in the analyses. Of these, 58\% were married, 50.5\% worked full-time, $23.9 \%$ part-time, and $48.6 \%$ were living in an urban environment.

\section{Procedure}

The French adaptation of the questionnaire was disseminated electronically with the software Evasys $^{\circledR}$. Data collection took place during the month of February 2017. The link to the questionnaire was disseminated through the Internet from the School of Health Sciences of Geneva with a short explanation of the study. The webpage with the link was transmitted and advertised on LinkedIn and Facebook by people or associations related to the Swiss investigator. The recipients were asked to spread the link in their own network. No compensation was offered for participation.

\section{Measures}

\section{Body dissatisfaction}

Body dissatisfaction was assessed with the Appearance Evaluation subscale of the Multidimensional Body-Self Relations Questionnaire (Cash, 2000), intended to be used with adults and adolescents. This includes seven items (e.g. I like my looks just the way they are) rated on a Likert scale ranging from 1 (definitively disagree) to 5 (definitely 
agree). The mean of these items gives a score of body satisfaction, since higher scores are indicative of more satisfaction with physical appearance and lower scores denote dissatisfaction and unhappiness with physical appearance. It was reversed to ease the interpretation of the results. The psychometric properties of the French adaptation of the questionnaire (Untas, Koleck, Rascle, \& Borteyrou, 2009) were close to that found for the English version by Brown, Cash, \& Mikulka (1990) and Cash (2000).

\section{Importance of appearance}

Importance of appearance was evaluated with the Centre for Appearance Research Salience Scale (Moss \& Rosser, 2012) which contains five items (e.g. I am usually conscious of my appearance) rated on a Likert scale ranging from 1 (strongly disagree) to 6 (strongly agree). This subscale showed a high level of internal consistency and robust item-total correlation (Moss \& Rosser, 2012). A higher total score indicates a higher salience of appearance within the self-concept.

\section{Aging anxiety}

Anxiety towards appearance changes that come with age was assessed with the Physical Appearance subscale of the Aging Anxiety Scale (Lasher \& Faulkender, 1993). This contains five items (e.g. I never dreaded looking old) rated on a Likert scale ranging from 1 (strongly agree) to 5 (strongly disagree). The subscale showed an adequate internal consistency in an adult sample aged between 18 and 74 (Lasher \& Faulkender, 1993). A higher score indicates a higher anxiety towards the effect of age on physical appearance.

\section{Depression}

Depression was assessed with the Hopkins Symptom Checklist-10 (HSCL-10; Strand, Dalgard, Tambs, \& Rognerud, 2003). This 10 -item version is derived from the 25 -item 
version, which is itself a shortened version of the SCL-90-R (Derogatis, 1983), with primarily items on depression (e.g. Feelings of worthlessness), and also anxiety (e.g Feeling fearful) or other symptoms (e.g. Difficulties falling asleep, staying asleep), with satisfactory psychometric properties. It has been used in many population surveys to assess psychological distress, with a better prediction of depression than of other diagnoses (Strand, et al., 2003). The use of the shorter versions has been recommended given its high correlation with the longer version. The ten items are rated on a Likert scale ranging from 1 (not at all) to 4 (extremely). Higher scores indicate greater depression.

\section{Anti-aging behaviors}

A series of yes/no questions asked participants if they dyed their hair, dieted or regularly participated in physical activity in order to manage age-related changes to their appearance. They were also asked if they had undergone surgical (e.g. breast augmentation, face lift, liposuction) and non-surgical cosmetic procedures (e.g., Botox, collagen injection, chemical peel), with yes/no response options.

\section{Socio-demographic variables}

A series of questions assessed age, marital and professional status. Height and weight were asked to calculate BMI $\left(\mathrm{kg} / \mathrm{m}^{2}\right)$.

Validated French versions of the Appearance Evaluation subscale (Untas, et al., 2009) and of the HSCL (Guelfi \& Dreyfus, 1997) were used. For the other items, a procedure of translation back-translation was carried out with the internal resources of the department (a psychologist and a bilingual dietician). 


\section{Statistical analyses}

There were no missing values to handle because answers were mandatory to complete the online questionnaire. The distribution of the score of depression was positively skewed, therefore we used Spearman's rank order correlations to assess the relationships between body dissatisfaction, importance of appearance, aging anxiety, depression, BMI and age. We also resorted to a heteroskedasticity-consistent standard error (HCSE) estimator of ordinary least squares (OLS) parameter estimates as recommended by Hayes and Cai (2007) to compute the multiple linear regression analysis, in order to avoid the effects that heteroskedasticity may have on inferential tests in OLS regression. Only the variables which showed bivariate correlations with depression were kept in the multivariate linear regression analysis. The frequencies of use of anti-aging behaviors (dying one's hair, dieting, physical activity, and surgical and non-surgical cosmetic procedures (combined)) reported were computed. Logistic regression analyses were performed to assess whether body dissatisfaction, importance of appearance, aging anxiety, BMI, and age were associated with any of these strategies. All statistical analyses were computed with the software IBM SPSS Statistics version 25 and the HCSE macro developed by Hayes and Cai (2007) for SPSS.

\section{Results}

\section{Correlational and regression analyses with depression as a dependent variable}

Descriptive statistics and Cronbach's alphas, which were all satisfactory, are displayed in Table 1. Depression showed weak positive correlations with importance of appearance, and aging anxiety and a moderate positive correlation with body dissatisfaction. No significant correlations were found between depression and BMI or age. Among the associations that appeared between the independent variables, aging 
anxiety was significantly positively associated with importance of appearance and negatively with BMI. There was also a strong positive relationship between body dissatisfaction and BMI, and a weak positive association between body dissatisfaction and age. Age and BMI also showed a small positive correlation.

To compute the multivariate linear regression analysis with depression as a criterion, we selected the variables that had showed bivariate correlations with depression as predictors: Body dissatisfaction, importance of appearance, and aging anxiety. The model displayed in Table 2 was significant $\left(F_{(3,327)}=23.17, p<.001, \operatorname{adj} R^{2}\right.$ $=0.21)$.

\section{Frequencies of anti-aging behaviors and variables associated with the probability of their use}

Regarding behaviors adopted to manage the effects of aging, $61.9 \%(n=205)$ of participants reported that they dyed their hair, 22.7\% $(n=75)$ were dieting (of whom, 49.3\% $(n=37)$ exhibited a BMI < 25), 72.2\% $(n=239)$ reported exercising regularly once a week or more. Cosmetic surgical procedures had been undertaken by $13.9 \%$ ( $n=$ 46) of participants. Regarding the type of procedure or part of the body involved, $7.3 \%$ $(n=24)$ mentioned the face or nose, $3.3 \%(n=11)$ breast augmentation or breast lift, $2.4 \%(n=8)$ breast reduction, $1.2 \%(n=4)$ the stomach and $0.9 \%(n=3)$ another part of the body. Non-surgical cosmetic procedures were reported by $13.0 \%(n=43)$ of participants: $7.3 \%(n=24)$ had had Botox, 3.0\% $(n=10)$ collagen injections, $2.1 \%(n=$ 7) chemical peeling and 3.6\% $(n=12)$ another procedure (without more indication).

As reported in the results of the logistic regression analyses computed with body dissatisfaction, importance of appearance, aging anxiety, BMI, and age as predictors (Table 3.), the probability of dying one's hair was higher with higher aging anxiety and an older age. The probability of dieting was higher with higher BMI, higher importance 
of appearance, and a younger age. The probability of doing physical activity was higher with a higher importance of appearance. Finally, the probability of undergoing surgical and non-surgical cosmetic procedures was higher with greater importance of appearance and aging anxiety.

\section{Discussion}

The first goal of the present study was to examine how body dissatisfaction, importance of appearance, aging anxiety, BMI, and age, were associated with depression in women in mid-life. Bivariate and multivariate associations showed that higher body dissatisfaction, placing greater importance of appearance and higher levels of aging anxiety were associated with greater depression. These results are in line with the relationship found between body dissatisfaction and depressive mood in younger women (Paxton, et al., 2006; Sharpe, et al., 2018), and with the results of one study conducted in women aged 42-52, which showed that being body dissatisfied was associated with a higher risk of depression symptoms (Jackson, et al., 2014). In the present study, aging anxiety and importance of appearance were also associated with depression. Aging anxiety and importance of appearance have been inconsistently correlated with body dissatisfaction and disordered eating in middle-aged women (McLean, et al., 2010; Slevec \& Tiggemann, 2011). The present results suggest they might play a role in depression, comparable to the higher risk for depression observed in women whose self-construct has been based on appearance and certain gender role traits (Bromberger \& Matthews, 1996; Saucier, 2004).

A second goal of this study was to evaluate the influence of body dissatisfaction, importance of appearance, aging anxiety, BMI, and age in the use of behaviors to manage age-related physical changes. Whereas the importance of appearance was 
associated with a higher probability of dieting, doing physical activity, and undergoing surgical or non-surgical cosmetic procedures, and aging anxiety was associated with higher probability of hair dying and undergoing surgical and non-surgical cosmetic procedures, body dissatisfaction was not related to any of these behaviors, unlike the results found in previous studies which showed impacts of body dissatisfaction on eating behaviors (Gagne, et al., 2012) or on the consideration to undertake cosmetic surgery (Slevec \& Tiggemann, 2010).

Dieting was associated with the importance of appearance and with a higher BMI. It has been shown that weight gain associated with aging appear to be a main concern for women, either for appearance or health reasons, but it was nevertheless seen as a personal failure and led to dieting (Winterich, 2007). In the present study, one fifth of the sample said that they were dieting to counteract the effect of aging, and half of the women were at a normal BMI. This may be concerning depending on what entails "dieting" for these women, which can range from "taking care of what I eat" to severe dietary restraint with potential negative consequences on health, particularly with age (Fallaz, Bernstein, Van Nes, Rouget, \& Morabia, 1999; Muscariello et al., 2016). But our survey did not comprise enough details to evaluate how severe was the diet. Dieting even at a normal weight nevertheless show that the pressure on thinness was still significant for a part of these women in mid-life.

Aging anxiety was not associated with the probability of dieting in the present study, in keeping with the study by Midlarsky and Nitzburg (2008). This is in contradiction with few studies which found direct correlations between concerns with the effect of age on appearance and drive for thinness in non-clinical women with a mean age of 40 (Gupta \& Schork, 1993). These studies are however rather old, and the possibilities that are now offered by the cosmetic industry and surgery might have 
changed the focus of the women struggling with anxiety of aging. Aging anxiety was actually involved in the probability of using behaviors to manage appearance changes due to age, such as dying one's hair, and surgical or non-surgical cosmetic procedures. Dying hair was reportedly used by two thirds of the sample and was also influenced by an older age: All women in the present sample may not have had grey hair yet. As observed in previous studies, grey hair is a common concern for women and the process of dying it is seen as "natural" aging (Clarke \& Griffin, 2007; Winterich, 2007). However, not all women decide to dye their hair and in the present results, this behavior was associated with aging anxiety.

Aging anxiety and importance of appearance were also key determinants of the probability of undergoing surgical or non-surgical cosmetic procedures. In the study by Clarke and Griffin (2007), women in their fifties were more in favor of using unnatural means (non-surgical and surgical cosmetic interventions) to keep a youthful appearance, compared to older women, suggesting a cohort effect regarding the acceptance of these more invasive beauty interventions.

Physical activity was reportedly used to counteract the effects of aging by $72 \%$ of the women in this study. This important percentage tends to show that the present sample was particularly active, but the results prevent us from determining their degree of physical activity. Health campaigns have encouraged people to be physically active to maintain their health. As underlined by Cameron, Ward, Mandville-Anstey, and Coombs (2019) in their review, with age, the preoccupations for appearance and for health tend to become intertwined. Being physically active is in contradiction with the representation of aging, associated with a decline of the body. Therefore it can be seen as a good strategy to maintain a youthful appearance by women in mid-life. 
This study has limitations. First, the data were collected in an online survey. Whilst this is a cost-effective means of data collection from a large geographic area and a large sample size was obtained, it can be subject to selection bias, such as attracting those with a higher level of education (Duffy, Smith, Terhanian, \& Bremer, 2005). To maximize the completion rate, and avoid overburdening participants, the survey was limited in length. Therefore, we did not ask detailed questions about women's reported diet or degree of physical activity. This limits the interpretation that can be drawn. The data were correlational, preventing causal interpretation. Finally the HSCL-10 used to assess depression contained two items related to anxiety, which may have increased the correlations found with aging anxiety, even if the items were not similar.

In conclusion, body dissatisfaction, importance of appearance, and aging anxiety were associated with greater depression in women in mid-life. The Western association of beauty with youth and the pressure to conform to it can be associated with distress amongst more vulnerable persons. Moreover, importance of appearance and aging anxiety were both associated with the probability of adopting behaviors to prevent physical changes due to aging, such as dying one's hair, dieting, being physically active, and undertaking surgical and non-surgical cosmetic procedures. The use of these behaviors emphasizes that for women, aging complicates the relationship to one's body and appearance. For many women, but not for all, with age, thinness remained of concern while youth became a preoccupation. Future research could investigate what distinguishes between women for whom aging-related changes to appearance are an issue, and those for whom natural aging is well accepted. 


\section{Disclosure statement}

The authors of this article have no conflict of interest to declare 


\section{References}

Bromberger, J. T., \& Matthews, K. A. (1996). A "feminine" model of vulnerability to depressive symptoms: a longitudinal investigation of middle-aged women. Journal of Personality and Social Psychology, 70(3), pp. 591-598.

Brown, T. A., Cash, T. F., \& Mikulka, P. J. (1990). Attitudinal body-image assessment: factor analysis of the Body-Self Relations Questionnaire. Journal of Personality Assessment, 55(1-2), pp. 135-144. doi:10.1080/00223891.1990.9674053

Cameron, E., Ward, P., Mandville-Anstey, S. A., \& Coombs, A. (2019). The female aging body: A systematic review of female perspectives on aging, health, and body image. Journal of Women \& Aging, 31(1), pp. 3-17. doi:10.1080/08952841.2018.1449586

Cash, T. F. (2000). MBSRQ user's manual (3rd ed.) Norfolk, VA: Old Dominion University Press.

Clarke, L. H., \& Griffin, M. (2007). The body natural and the body unnatural: Beauty work and aging. Journal of Aging Studies, 21(3), pp. 187-201. doi:10.1016/j.jaging.2006.11.001

Derogatis, L. (1983). SCL-90-R, Administration, scoring and procedures manual (2nd ed.) Baltimore, MD: Procedures Psychometric Research.

Duffy, B., Smith, K., Terhanian, G., \& Bremer, J. (2005). Comparing data from online and face-to-face surveys. International Journal of Market Research, 47(6), pp. 615-639.

Fallaz, A. F., Bernstein, M., Van Nes, M. C., Rouget, P., \& Morabia, A. (1999). "Weight loss preoccupation in aging women": a review. Journal of Nutrition Health and Aging, 3(3), pp. 177-181.

Gagne, D. A., Von Holle, A., Brownley, K. A., Runfola, C. D., Hofmeier, S., Branch, K. E., \& Bulik, C. M. (2012). Eating disorder symptoms and weight and shape concerns in a large web-based convenience sample of women ages 50 and above: Results of the gender and body image (GABI) study. International Journal of Eating Disorders, 45(7), pp. 832-844. doi:10.1002/eat.22030

Goncalves, S. F., Silva, E., \& Gomes, A. R. (2015). The Influence of BMI and Predictors of Disordered Eating and Life Satisfaction on Postmenopausal Women. Journal of Women \& Aging, 27(2), pp. 140-156. doi:10.1080/08952841.2014.928496

Guelfi, J. D., \& Dreyfus, J. F. (1997). La symptom check-list SCL-90R. In J. D. Guelfi (Ed.), L'évaluation clinique standardisée en psychiatrie. Tome 1. Boulogne: Editions médicales Pierre Fabre.

Gupta, M. A., \& Schork, N. J. (1993). Aging-related concerns and body image: possible future implications for eating disorders. International Journal of Eating Disorders, 14(4), pp. 481-486.

Hayes, A. F., \& Cai, L. (2007). Using heteroskedasticity-consistent standard error estimators in OLS regression: an introduction and software implementation. Behavior Research Methods, 39(4), pp. 709-722.

Hurd, L. C. (2000). Older women's body image and embodied experience: An exploration. Journal of Women \& Aging, 12(3-4), pp. 77-97. doi:10.1300/J074v12n03_06

Jackson, K. L., Janssen, I., Appelhans, B. M., Kazlauskaite, R., Karavolos, K., Dugan, S. A., . . Kravitz, H. M. (2014). Body image satisfaction and depression in midlife women: the Study of Women's Health Across the Nation (SWAN). 
Archives of Womens Mental Health, 17(3), pp. 177-187. doi:10.1007/s00737014-0416-9

Johnson, F., \& Wardle, J. (2005). Dietary restraint, body dissatisfaction, and psychological distress: A prospective analysis. Journal of Abnormal Psychology, 114(1), pp. 119-125. doi:10.1037/0021-843x.114.1.119

Kilpela, L. S., Becker, C. B., Wesley, N., \& Stewart, T. (2015). Body Image in Adult Women: Moving Beyond the Younger Years. Advances in Eating Disorders, 3(2), pp. 144-164. doi:10.1080/21662630.2015.1012728

Lasher, K. P., \& Faulkender, P. J. (1993). Measurement of Aging Anxiety Development of the Anxiety About Aging Scale. International Journal of Aging \& Human Development, 37(4), pp. 247-259. doi: 10.2190/1u69-9au2-V6lh-9y11

Mangweth-Matzek, B., \& Hoek, H. W. (2017). Epidemiology and treatment of eating disorders in men and women of middle and older age. Current Opinion in Psychiatry, 30(6), pp. 446-451. doi:10.1097/Yco.0000000000000356

Mangweth-Matzek, B., Hoek, H. W., \& Pope, H. G. (2014). Pathological eating and body dissatisfaction in middle-aged and older women. Current Opinion in Psychiatry, 27(6), pp. 431-435. doi:10.1097/Yco.0000000000000102

Mangweth-Matzek, B., Rupp, C. I., Hausmann, A., Assmayr, K., Mariacher, E., Kemmler, G., . . . Biebl, W. (2006). Never too old for eating disorders or body dissatisfaction: a community study of elderly women. International Journal of Eating Disorders, 39(7), pp. 583-586.

McLaren, L., \& Kuh, D. (2004). Body dissatisfaction in midlife women. Journal of Women \& Aging, 16(1-2), pp. 35-54. doi:10.1300/J074v16n01_04

McLean, S. A., Paxton, S. J., \& Wertheim, E. H. (2010). Factors Associated with Body Dissatisfaction and Disordered Eating in Women in Midlife. International Journal of Eating Disorders, 43(6), pp. 527-536. doi:10.1002/eat.20737

Midlarsky, E., \& Nitzburg, G. (2008). Eating Disorders in Middle-Aged Women. Journal of General Psychology, 135(4), pp. 393-407. doi:Doi 10.3200/Genp.135.4.393-408

Moss, T. P., \& Rosser, B. A. (2012). The moderated relationship of appearance valence on appearance self consciousness: development and testing of new measures of appearance schema components. PLoS One, 7(11), p e50605. doi:10.1371/journal.pone.0050605

Muscariello, E., Nasti, G., Siervo, M., Di Maro, M., Lapi, D., D'Addio, G., \& Colantuoni, A. (2016). Dietary protein intake in sarcopenic obese older women. Clinical Interventions in Aging, 11, pp. 133-140. doi:10.2147/CIA.S96017

Neumark-Sztainer, D., Paxton, S. J., Hannan, P. J., Haines, J., \& Story, M. (2006). Does body satisfaction matter? Five-year longitudinal associations between body satisfaction and health behaviors in adolescent females and males. Journal of Adolescent Health, 39(2), pp. 244-251. doi:10.1016/j.jadohealth.2005.12.001

Paxton, S. J., Neumark-Sztainer, D., Hannan, P. J., \& Eisenberg, M. E. (2006). Body dissatisfaction prospectively predicts depressive mood and low self-esteem in adolescent girls and boys. Journal of Clinical Child and Adolescent Psychology, 35(4), pp. 539-549. doi:DOI 10.1207/s15374424jccp3504_5

Peat, C. M., Peyerl, N. L., \& Muehlenkamp, J. J. (2008). Body image and eating disorders in older adults: a review. Journal of General Psychology, 135(4), pp. 343-358. doi:10.3200/GENP.135.4.343-358

Runfola, C. D., Von Holle, A., Trace, S. E., Brownley, K. A., Hofmeier, S. M., Gagne, D. A., \& Bulik, C. M. (2013). Body dissatisfaction in women across the 
lifespan: results of the UNC-SELF and Gender and Body Image (GABI) studies. European Eating Disorders Review, 21(1), pp. 52-59. doi:10.1002/erv.2201

Saucier, M. G. (2004). Midlife and beyond: Issues for aging women. Journal of Counseling and Development, 82(4), pp. 420-425. doi:10.1002/j.15566678.2004.tb00329.x

Sharpe, H., Griffiths, S., Choo, T. H., Eisenberg, M. E., Mitchison, D., Wall, M., \& Neumark-Sztainer, D. (2018). The relative importance of dissatisfaction, overvaluation and preoccupation with weight and shape for predicting onset of disordered eating behaviors and depressive symptoms over 15 years. International Journal of Eating Disorders, 51(10), pp. 1168-1175. doi:10.1002/eat.22936

Slevec, J., \& Tiggemann, M. (2010). Attitudes toward Cosmetic Surgery in MiddleAged Women: Body Image, Aging Anxiety, and the Media. Psychology of Women Quarterly, 34(1), pp. 65-74. doi:DOI 10.1111/j.14716402.2009.01542.x

Slevec, J., \& Tiggemann, M. (2011). Predictors of body dissatisfaction and disordered eating in middle-aged women. Clinical Psychology Review, 31(4), pp. 515-524. doi:10.1016/j.cpr.2010.12.002

Stice, E. (2002). Risk and maintenance factors for eating pathology: a meta-analytic review. Psychological Bulletin, 128(5), pp. 825-848.

Stice, E., Gau, J. M., Rohde, P., \& Shaw, H. (2017). Risk factors that predict future onset of each DSM-5 eating disorder: Predictive specificity in high-risk adolescent females. Journal of Abnormal Psychology, 126(1), pp. 38-51. doi:10.1037/abn0000219

Strand, B. H., Dalgard, O. S., Tambs, K., \& Rognerud, M. (2003). Measuring the mental health status of the Norwegian population: A comparison of the instruments SCL-25, SCL-10, SCL-5 and MHI-5 (SF-36). Nordic Journal of Psychiatry, 57(2), pp. 113-118. doi:10.1080/08039480310000932

Takahashi, Y., Fukushima, Y., Kondo, K., \& Ichihashi, M. (2017). Facial skin photoaging and development of hyperpigmented spots from children to middle-aged Japanese woman. Skin Research and Technology, 23(4), pp. 613-618. doi:10.1111/srt.12380

Tiggemann, M., \& Lynch, J. E. (2001). Body image across the life span in adult women: The role of self-objectification. Developmental Psychology, 37(2), pp. 243-253. doi:10.1037//0012-1649.37.2.243

Untas, A., Koleck, M., Rascle, N., \& Borteyrou, X. (2009). Psychometric Properties of the French Adaptation of the Multidimensional Body Self Relations Questionnaire-Appearance Scales. Psychological Reports, 105(2), pp. 461-471. doi:10.2466/Pr0.105.2.461-471

Webster, J., \& Tiggemann, M. (2003). The relationship between women's body satisfaction and self-image across the life span: the role of cognitive control. Journal of Genetic Psychology, 164(2), pp. 241-252. doi:10.1080/00221320309597980

Winterich, J. A. (2007). Aging, Femininity, and the Body: What Appearance Changes Mean to Women with Age. [journal article]. Gender Issues, 24(3), pp. 51-69. doi:10.1007/s12147-007-9045-1 
Table 1. Descriptive statistics (Means, standard deviations $(S D)$, Cronbach's alphas $(C$ 's $\alpha)$ ) and Spearman's correlations $(N=331)$

\begin{tabular}{|c|c|c|c|c|c|c|c|c|c|}
\hline & \multirow[b]{2}{*}{ Variables } & \multirow[b]{2}{*}{ Mean } & \multirow[b]{2}{*}{$S D$} & \multirow[b]{2}{*}{$C^{\prime} s \alpha$} & \multicolumn{5}{|c|}{ Spearman's Correlations } \\
\hline & & & & & 1 & 2 & 3 & 4 & 5 \\
\hline 1 & Depression & 1.69 & 0.54 & 0.87 & -------- & & & & \\
\hline 2 & Body dissatisfaction & 3.44 & 0.79 & 0.88 & $0.31 * *$ & -------- & & & \\
\hline 3 & Importance of appearance & 3.89 & 1.06 & 0.86 & $0.19 * *$ & -0.04 & -------- & & \\
\hline 4 & Aging anxiety & 2.65 & 0.84 & 0.75 & $0.32 * *$ & 0.10 & $0.36^{* *}$ & ------- & \\
\hline 5 & BMI & 23.77 & 4.30 & & -0.04 & $0.52^{* *}$ & -0.11 & $-0.17 * *$ & -------- \\
\hline 6 & Age & 53.34 & 5.19 & & 0.09 & $0.19 * *$ & 0.08 & -0.08 & $0.16^{* *}$ \\
\hline
\end{tabular}

BMI body mass index; ** $\mathrm{p}<.01$ (bilateral test) 
Table 2. Coefficients for the linear regression analysis with depression as a criterion and body dissatisfaction, importance of appearance and aging anxiety as predictors

\begin{tabular}{lccc}
\hline \multicolumn{1}{c}{ Independent variable } & $\boldsymbol{B}$ & $\boldsymbol{S} \boldsymbol{t}$ & $\boldsymbol{t}$ \\
\hline Body dissatisfaction & .24 & .04 & $5.73^{* * *}$ \\
Importance of appearance & .07 & .03 & $2.73^{* *}$ \\
Aging anxiety & .13 & .03 & $3.74^{* * *}$ \\
\hline$* * *$ pr.001;** p<.01 & &
\end{tabular}

$* * * \mathrm{p}<.001 ; * * \mathrm{p}<.01$ 
Table 3. Logistic regression odd ratios $(\operatorname{Exp}(B))$ and confidence intervals $(C I(95 \%))$ for variables predicting the probability to use anti-aging behaviors $(N=331)$

\begin{tabular}{|c|c|c|c|c|c|c|c|c|}
\hline & \multicolumn{2}{|c|}{ Hair dying } & \multicolumn{2}{|c|}{ Diet } & \multicolumn{2}{|c|}{ Physical activity } & \multicolumn{2}{|c|}{$\begin{array}{c}\text { (non-)surgical } \\
\text { procedures }\end{array}$} \\
\hline & $\operatorname{Exp}(B)$ & $C I(95 \%)$ & $\operatorname{Exp}(B)$ & $C I(95 \%)$ & $\operatorname{Exp}(B)$ & CI $(95 \%)$ & $\operatorname{Exp}(B)$ & $C I(95 \%)$ \\
\hline Body dissatisfaction & 0.868 & $0.60-1.27$ & 1.42 & $0.95-2.13$ & 1.08 & $0.74-1.59$ & 0.73 & $0.47-1.13$ \\
\hline Importance of appearance & 1.01 & $0.79-1.29$ & $1.38 *$ & $1.03-1.86$ & $1.47 * *$ & $1.14-1.90$ & $1.37 *$ & $1.03-1.82$ \\
\hline Aging anxiety & $2.85 * * *$ & $1.98-4.10$ & 1.05 & $0.72-1.53$ & 0.99 & $0.71-1.38$ & $1.66^{* *}$ & $1.15-2.39$ \\
\hline BMI & 1.03 & $0.96-1.10$ & $1.14 * * *$ & $1.06-1.23$ & 0.97 & $0.91-1.04$ & 1.02 & $0.94-1.10$ \\
\hline Age & $1.08 * *$ & $1.03-1.13$ & $0.94 *$ & $0.89-0.99$ & 1.03 & $0.98-1.08$ & 1.05 & $0.99-1.10$ \\
\hline
\end{tabular}

$* \mathrm{p}<.05 ; * * \mathrm{p}<.01 ; * * * \mathrm{p}<.001$ 